\title{
LOW IN VITRO THIRD-BODY WEAR ON TOTAL HIP PROSTHESES INDUCED BY CALCIUM SULPHATE USED FOR LOCAL ANTIBIOTIC THERAPY
}

\author{
R. Heuberger ${ }^{1, *}$, P. Wahl ${ }^{2}$, J. Krieg ${ }^{1}$ and E. Gautier ${ }^{2}$ \\ ${ }^{1}$ RMS Foundation, Bettlach, Switzerland \\ ${ }^{2}$ Department of Orthopaedic Surgery, HFR Fribourg - Cantonal Hospital, Switzerland
}

\begin{abstract}
In case of implant associated infection, implant preservation is associated with high failure rates. Therefore, a removal or exchange of the implant is most often mandatory for treatment success. Alternatively, under certain conditions, local antibiotic delivery can be applied - preserving the implant, using for example calcium sulphate as a resorbable carrier. In this work, third-body wear on total hip prostheses caused by calcium sulphate particles was tested in a hip simulator. Inlays made of ultra-high-molecular-weight polyethylene (UHMWPE) and cross-linked polyethylene (XLPE) against $28 \mathrm{~mm}$ CoCrMo heads and $36 \mathrm{~mm}$ alumina pairings were tested in triplicate, both with and without calcium sulphate particles in the test liquid.

Neither the alumina articulations nor the CoCrMo heads were affected by the calcium sulphate particles since calcium sulphate is a relatively soft material. The polyethylene inlays showed 39-89\% higher wear during exposure compared to references, but wear returned to normal when no more particles were added. Thus, calcium sulphate might be used as antibiotic carrier even in the presence of total hip prostheses without fearing excessive third-body wear.
\end{abstract}

Keywords: Third-body wear, total hip prosthesis, calcium sulphate, gypsum, plaster of Paris, antibiotic carrier, ultra-high-molecular-weight polyethylene, cross-linked polyethylene, vitamin E.

*Address for correspondence:

Roman Heuberger

RMS Foundation

Bischmattstr. 12

CH-2544 Bettlach, Switzerland

Telephone Number: +41326441474

E-mail: roman.heuberger@rms-foundation.ch

\section{Introduction}

Medical implants are increasingly used in various domains. While standard surgical techniques and prophylactic antibiotics allow keeping overall infection rates relatively low, implants remain very susceptible to bacterial colonisation (Elek and Conen, 1957; Zimmerli et al., 1982; Darouiche, 2001). Contamination with a very low number of bacteria, some hundred colony forming units, is enough to develop infection (Elek and Conen, 1957; Zimmerli et al., 1982; Darouiche, 2001). Most often, infection cannot be eradicated without removal of the implant, because of biofilm formation at the device's surface and other particularities of implant-related infections, such as poor local antibiotic penetration and leucocyte function impairment (Zimmerli et al., 1982, 1984; Widmer et al., 1990; Darouiche, 2004; Zimmerli et al., 2004; Osmon et al., 2013). Considering reoperation, functional losses and risks, this leads to high costs, not only for the patient's health, but also for the entire health system (Wolf et al., 2011; Kurtz et al., 2012; Vanhegan et al., 2012).

Removal might be particularly problematic for permanent implants such as joint replacements. Under certain circumstances, the infection might reasonably be treated while preserving the implant (Zimmerli et al., 2004; Marculescu et al., 2006; Koyonos et al., 2011; Lora-Tamayo et al., 2013; Osmon et al., 2013). The criteria leading to the recommendations for removal or attempt of implant preservation are listed and discussed elsewhere (Zimmerli et al., 2004; Osmon et al., 2013). However, success rates are only around 50-60\% in large series, failures requiring later removal, exchange, fusions or amputations (Zimmerli et al., 2004; Marculescu et al., 2006; Koyonos et al., 2011; Lora-Tamayo et al., 2013; Osmon et al., 2013).

In order to improve antibiotic treatment efficacy, local application has become common practice in orthopaedic surgery (Buchholz and Engelbrecht, 1970; Iarikov et al., 2012; Kluin et al., 2013). There is a large variety of antibiotic carrier materials ranging from nonbiodegradable bone cement, which is made of polymethyl methacrylate (PMMA), to biodegradable materials such as hydroxyapatite, calcium phosphate and calcium sulphate, collagen, fibrin, or polymers such as polylactides, polyglycose or polyurethanes (Kanellakopoulou and Giamarellos-Bourboulis, 2000; Kelly et al., 2001, Kluin et al., 2013). Gross functional impairment of a joint might be avoided using soft and biodegradable carrier materials. 
The clinical problem of infection treatment using calcium sulphate pellets is illustrated by a case in the appendix. Calcium sulphate had been chosen as drug carrier material because it is a resorbable material benefiting from a long lasting and broad medical experience, that appears to be very suitable for local delivery of antibiotics (Kelly et al., 2001; Rauschmann et al., 2005; Bibbo and Patel, 2006; Wahl et al., 2011a). The fact that it is resorbable renders it ideal for the delivery of antibiotics: together with drug release, the surface of the calcium sulphate pellets is dissolved, making biofilm formation impossible contrary to what is observed on antibiotic loaded PMMA (Neut et al., 2001; Van De Belt et al., 2001; Anagnostakos et al., 2008). Antibiotics are released over a time period of more than 10 days (Wichelhaus et al., 2001; Rauschmann et al., 2005; Wahl et al., 2011b; Wang et al., 2011) up to 4 or even 6 weeks, depending on the antibiotic used (Rönn et $a l ., 2014)$. This corresponds approximately to the duration of antibiotic treatment usually recommended for bone and joint infections (Lew and Waldvogel, 2004; Zimmerli et al., 2004; Osmon et al., 2013). Heat production at rehydration of calcium sulphate hemihydrate is much lower than during PMMA polymerisation, which is beneficial as most antibiotics have low heat resistance (Doadrio et al., 2004). Another advantage of calcium sulphate is that this material is relatively soft. With a Mohs hardness of 2, it can be scratched with a finger nail.

However, third body wear of the prostheses caused by particles freed during dissolution remains an issue. For example, particles originating from the bone cement do induce excessive wear (Hauptmann et al., 2008). Worst case scenarios are well illustrated in clinical reports of failures due to ceramic particles from fractured components (Kohn and Pape, 2007; Pazzaglia et al., 2011), hydroxyapatite particles originating from the coating of the cup or the stem (Morscher et al., 1998; Røkkum et al., 2002) or metal particles (Scott et al., 2000), found embedded in polymer liners. In vitro third-body wear tests showed that both the polymer liners (Oral et al., 2006; Kubo et al., 2009) and the metallic heads are scratched by PMMA particles (Bragdon et al., 2003, 2005). Tests performed with large particles (Ø 160-500 $\mu \mathrm{m}$, Wang and Essner, 2001; Affatato et al., 2002; Wang et al., 2002; Wang and Schmidig, 2003) lead to higher wear of the polymer components than smaller particles of about Ø $30 \mu \mathrm{m}$ (Bragdon et al., 2003, 2005). PMMA patches were found on the head leading to abrasion of the polymeric counterpart (Kubo et al., 2009; Sorimachi et al., 2009). Ceramic heads are not affected by PMMA third-bodies (Wang and Essner, 2001; Wang et al., 2002; Grupp et al., 2014). Hip simulator tests performed with ceramic particles lead not only to higher polymer wear (Bragdon et al., 2003; Oberbach et al., 2009b; Hintner et al., 2012) but also to more scratches on metallic heads (Bragdon et al., 2003; Hintner et al., 2012) or to scratches and grain breakouts on ceramic heads (Oberbach et al., 2005, 2009a, 2009b; Hintner et al., 2012). Ceramic-onceramic articulations are not affected by small ceramic particles (Oberbach et al., 2009b). This study aimed at quantifying wear induced in vitro by calcium sulphate particles on total hip prostheses.

\section{Materials and Methods}

\section{Hip simulator tests}

In vitro hip simulator tests were conducted according to ISO 14242-1:2012 and ISO 14242-2:2000. Inlays made of ultra-high-molecular-weight polyethylene (UHMWPE) (sterilised with $30 \pm 5 \mathrm{kGy} \gamma$-irradiation, \# 55.43.2805) and cross-linked polyethylene containing vitamin E (XLPE, cross-linked with $100 \pm 5 \mathrm{kGy} \gamma$-irradiation, trade name Vitamys $^{\circledR}, \#$ 52.34.0134) were in articulation against Ø 28 mm CoCrMo heads (\# 2.30.011). Additionally, alumina pairings $\left(\varnothing 36 \mathrm{~mm}\right.$, Bionit ${ }^{\circledR} 2$, inlays $36 \mathrm{GG}$, heads $36 \mathrm{M} \mathrm{12/14)}$ were investigated. The tests were performed with at least three pairings each. All prosthesis components were of the seleXys ${ }^{\circledR}$ line and were provided by Mathys, Bettlach, Switzerland.

Prior to the test, the polymer inlays were pre-soaked in the test liquid in order to reduce the amount of soaking during the simulator test. The tests were conducted on a servo hydraulic hip- and spine simulator (Endolab, Thansau/Rosenheim, Germany, type C6/2-07). It offers six wear stations and two soaking stations. The inlays were fixed in titanium cups (seleXys ${ }^{\circledR}$ uncemented pressfit cups, for polymer inlays: \# 55.41.0050, for ceramic inlays: unicup UC 56) positioned with $30^{\circ}$ inclination and the load was introduced through the cup onto the inlay and the head. Considering $10^{\circ}$ inclination of the femoral component, total inclination was $40^{\circ}$. The soaking samples (only for polymer inlays) were positioned upside down (inlay beyond the head). The same load profile was applied onto the soaking samples, but without motion.

The test chambers were covered with polymer bellows. Each test chamber was equipped with a heater and a temperature sensor, controlling that the test liquid remained at $37 \pm 1{ }^{\circ} \mathrm{C}$. A fill-level sensor controlled that the articulation partners could not run dry. The test liquid was produced by dilution with deionised water of new-born calf serum from New Zealand (Thermo Fisher Scientific, Waltham, MA, USA, lot 8097790) to a protein concentration of $30 \mathrm{~g} / \mathrm{L}$, according to the ISO 14242-1:2012 standard. Sodium azide and ethylenediaminetetraacetic acid disodium salt dihydrate (both p.a., Sigma-Aldrich Chemie, Steinheim, Germany, sodium azide: \# 71290, ethylenediaminetetraacetic acid disodium salt dihydrate: \# 34549) were added at $2 \mathrm{~g} / \mathrm{L}$ and $3 \mathrm{~g} / \mathrm{L}$ respectively, to inhibit bacterial growth and to bind metallic ions. To remove bacteria and other possible contaminants from the test liquid, it was filtered through $0.2 \mu \mathrm{m}$ filters (Nalgene ${ }^{\circledR}$ from Thermo Fisher Scientific, \# 567-0020). The test liquid was either freshly prepared prior to the test or stored at $-20^{\circ} \mathrm{C}$ and thawed before its use. For the tests performed in the presence of calcium sulphate particles, $10 \mathrm{~g} / \mathrm{L}$ calcium sulphate hemihydrate (Fig. 1, Ø 0.5-100 $\mu \mathrm{m}$, trivial name: plaster of Paris, VWR, Radnor, PA, USA, \# 22441.296) was added to the standard test liquid immediately before the start-up of the experiment. This concentration was chosen to clearly exceed the solubility of $2 \mathrm{~g} / \mathrm{L}$ in water (Lide, 2004). In contact with water, calcium sulphate hemihydrate immediately forms the more stable calcium sulphate dihydrate, i.e. gypsum. If not specified otherwise, 
the term "calcium sulphate" refers in this work to the calcium sulphate dihydrate.

For the hip simulation, the load-motion cycle according to ISO 14242-1 lasted one second and was repeated continually, simulating the conditions while walking. The load and motions were measured and adjusted digitally. Every 500,000 cycles, the testing chambers were taken apart, cleaned and the inlays were weighed according to ISO 14242-2. Before weighing, the samples were cleaned in an ultrasonic bath first immersed in deionised water, then in water with cleaning detergent (Borer Chemie, Zuchwil, Switzerland, deconex 12 PA) followed by two washes with deionised water. After $5 \mathrm{~min}$ immersion in isopropanol (99 \%, Thommen-Furler, Rüti b. Bühren, Switzerland, \# 172-VL50TN) they were dried in vacuum (pressure $<10 \mathrm{~Pa}$ ). The weighing was performed on a balance with an accuracy of $0.01 \mathrm{mg}$ (Mettler Toledo Intl., Columbus, $\mathrm{OH}, \mathrm{USA}, \mathrm{AX} 205)$. Each sample was weighed twice and the measurement was repeated if the difference between the two values was larger than $0.1 \mathrm{mg}$. After weighing, the test chambers were cleaned, reassembled, filled with fresh test liquid and switched to another measuring station of the simulator. The test was finished after 5 million cycles (MC). Polymer inlays tested with calcium sulphate were then subject to 1 million additional cycles without calcium sulphate particles. The wear rate of each sample was determined with linear fits of the weights (without taking the starting point into account) according to ISO 14242-2. It was corrected for the mass gain of the soaking sample.

\section{Powder examination}

Images of the calcium sulphate hemihydrate particles were taken using scanning electron microscopy (SEM; Carl Zeiss, Jena, Germany, EVO MA25). The size distribution was analysed with a laser diffractometer (Beckman Coulter, Krefeld, Germany, LS 13320, measured with dry powder system).

\section{Sample examination}

The dimension of the ceramic heads and inlays was measured with a coordinate measuring machine (Hexagon, Stockholm, Sweden, Etalon-Derby, measured at Mathys, Mörsdorf, Germany). The articulating surfaces of the heads and inlays were examined qualitatively with a binocular microscope (Leica Microsystems, Wetzlar, Germany, M205A) equipped with multifocus to increase the depth of field. Selected samples were additionally investigated using SEM equipped with energy-dispersive X-ray spectroscopy (EDX; Oxford Instruments, Abingdon, UK, INCA Energy 350 with x-Max 50 Silicon Drift Detector). The roughness and the topography of the metallic heads and of several polymer inlays were investigated using confocal microscopy (NanoFocus, Oberhausen, Germany, $\mu$ Surf, data processing with $\mu$ Soft analysis XT, V6.2.6122). The roughness of the ceramic samples was determined with contact profilometry (Jenoptik, Jena, Germany, hommel etamic T8000, tip TK50, measured at Mathys, Mörsdorf, Germany). The roughness parameters were determined according to ISO 4287, 4288 and 13565-2. Selected polymer inlays were investigated using a Fourier transform
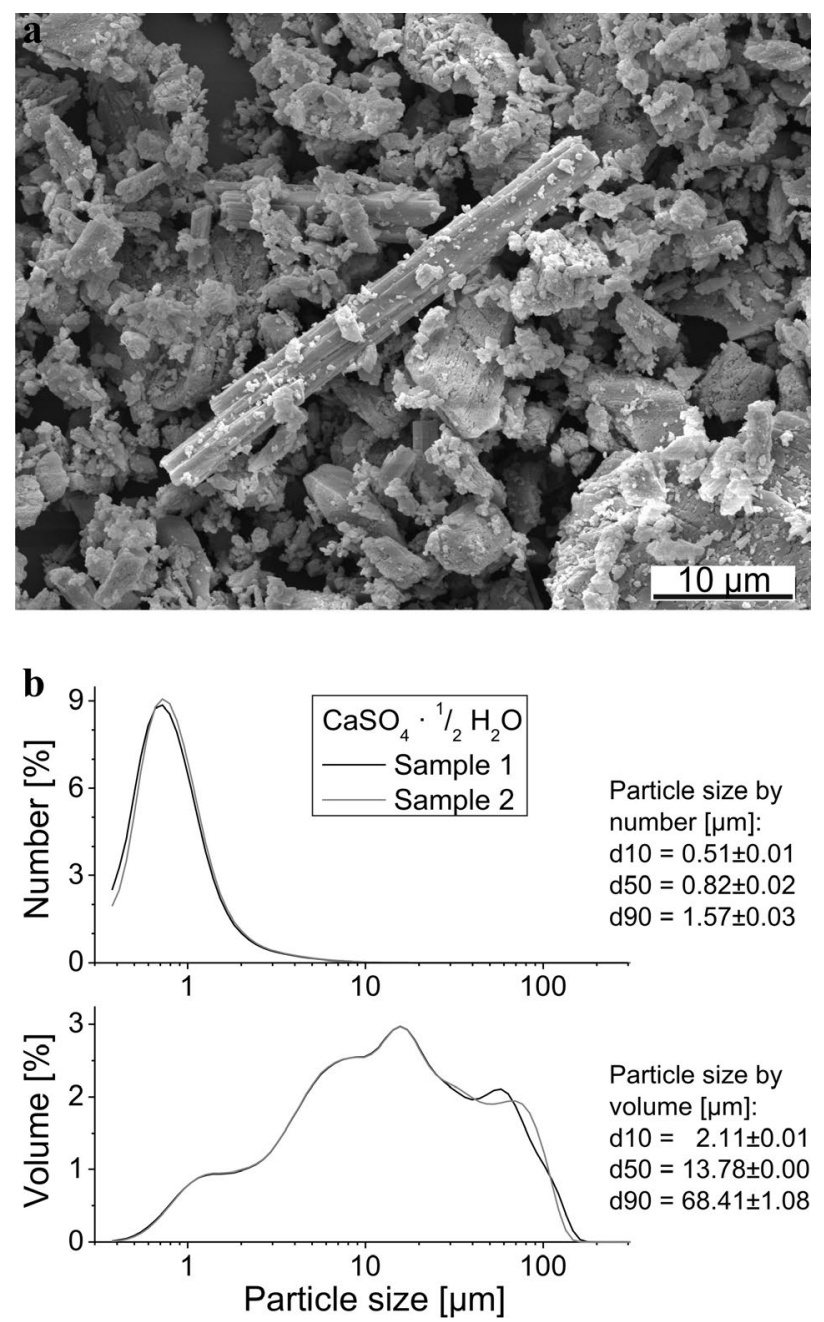

Fig. 1. Calcium sulphate hemihydrate particles: (a) SEM image, (b) size distribution determined with laser diffractometry.

infrared microscope (FT-IR; Bruker, Billerica, MA, USA, LUMOS).

\section{Statistical analysis}

Results are represented as average \pm standard deviation. Statistical testing was carried out using an independent two-sided Student's $t$-test with unequal variances.

\section{Results}

\section{Wear}

In the presence of calcium sulphate particles in the test liquid, the wear rate of the UHMWPE inlays was slightly higher in the first half of the experiment with $41 \pm 4 \mathrm{mg} /$ $\mathrm{MC}$ than during the second half, were it reduced to $31 \pm 5$ $\mathrm{mg} / \mathrm{MC}$ (Fig. 2a, $p=0.05$ ). Mean overall wear rate was $36 \pm 5 \mathrm{mg} / \mathrm{MC}$ (Fig. 3). The wear rate of the XLPE inlays remained constant with $9 \pm 2 \mathrm{mg} / \mathrm{MC}$ over the whole $5 \mathrm{MC}$. The amount of the soaking was with $0.7 \mathrm{mg} / \mathrm{MC}$ and $0.2 \mathrm{mg} / \mathrm{MC}$ relatively small for both the UHMWPE and the XLPE respectively. Wear was 39-89 \% higher in the presence of calcium sulphate particles compared to 

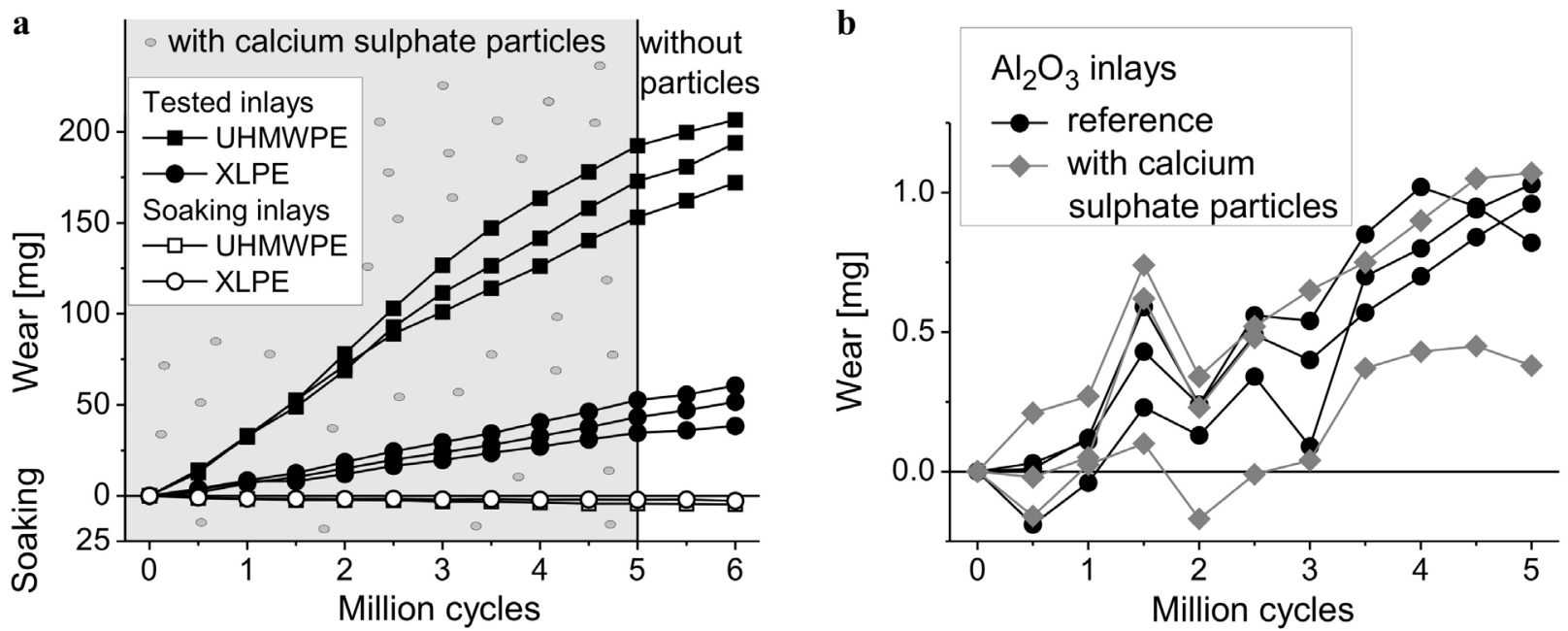

Fig. 2. (a) Wear and soaking of the polymer inlays tested in presence of calcium sulphate particles in the test liquid. The test was subsequently continued for $1 \mathrm{MC}$ without calcium sulphate particles. (b) Wear of the ceramic inlays tested with and without calcium sulphate particles.

Fig. 3. In vitro wear rate of the inlays of total hip prostheses. The polymer inlays were in articulation with Ø $28 \mathrm{~mm}$ CoCrMo heads. The alumina inlays were tested against $\varnothing 36$ alumina heads. Statistics: 2-sided Student's $t$-test with a: $p<0.07$, b: $p<0.03$ and $\mathrm{c}: p<0.01$ $(n=3$ to 6$)$. All other probabilities $p$ were higher than 0.1 .

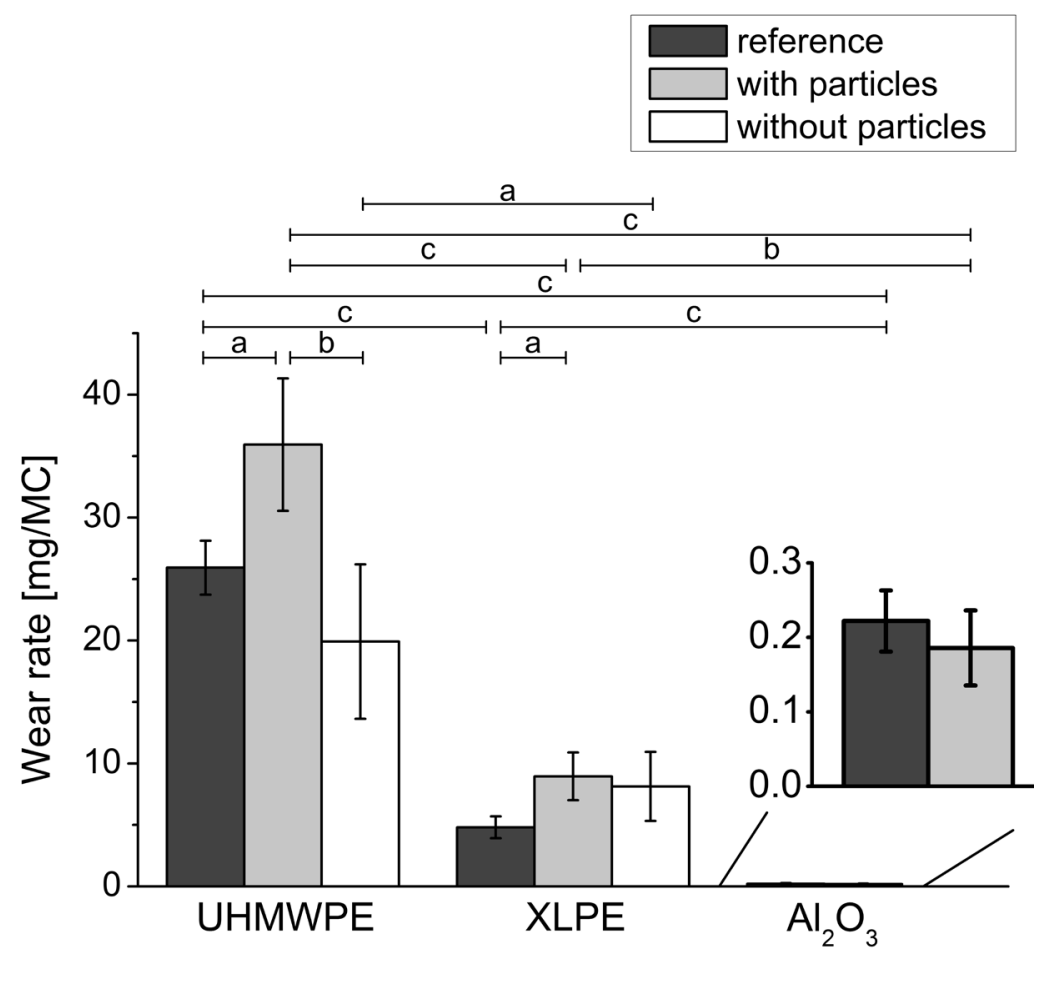

the references tested without particles in the test liquid (Fig. 3). The wear rates decreased when no more particles were added. For the UHWMPE it was in the range of the reference samples, while for the XLPE inlays it remained slightly higher than the references.

The measured weight of the ceramic inlays did highly scatter (Fig. 2b). Most likely this was because of protein remnants on the sample surface persisting despite the cleaning procedure. Additionally, there were metallic traces on the inlay's backside from the cup. Unfortunately, one inlay was damaged on the rim during the cleaning/weighing procedure. Therefore, the results of one inlay could only be used until $2.5 \mathrm{MC}$. The wear rates were $0.19 \pm 0.05 \mathrm{mg} /$ $\mathrm{MC}$ with calcium sulphate particles and $0.22 \pm 0.04 \mathrm{mg} /$ $\mathrm{MC}$ without. The weight of the ceramic heads increased continually, which went together with the observation of corrosion products from the metallic cone deposited on the inner cone of the heads. Thus, no reliable wear rate could be determined for the heads. No significant difference was obtained for the measured dimensions of the inlays and heads determined before and after the simulator test.

\section{Examination of the articulating surfaces}

The metallic heads and the polymer inlays exhibited few scratches (Fig. 4), but there was no obvious difference between the articulations tested with and without calcium sulphate particles. In agreement, the mean arithmetic roughness $\mathrm{R}_{\mathrm{a}}$ determined on the CoCrMo heads after the test revealed values between 1 and $3 \mathrm{~nm}$ for both with and without calcium sulphate particles in the test liquid. 

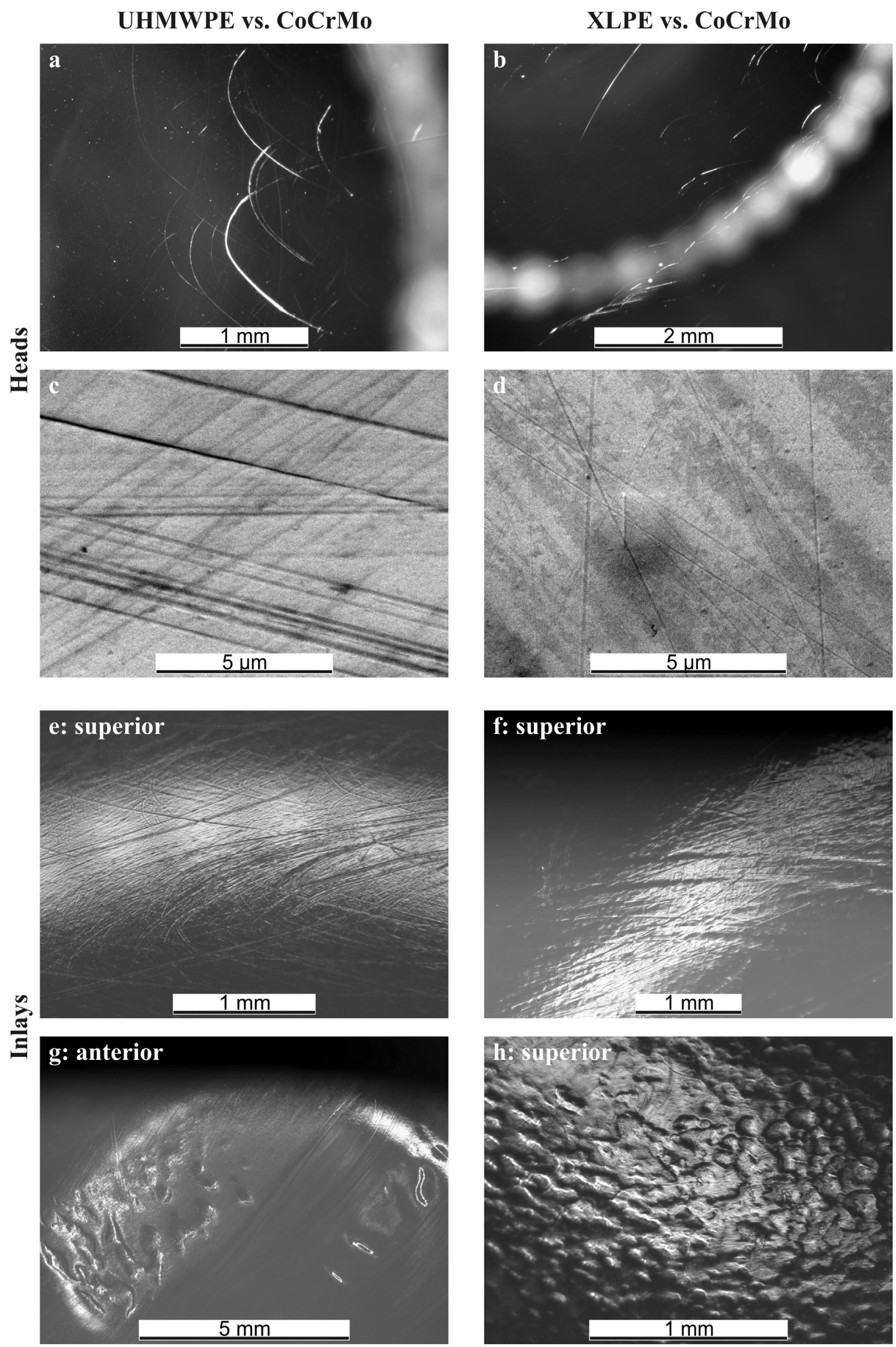

Fig. 4. Images of the CoCrMo heads (a-d) and the polymer inlays (e-h) after the hip simulator test with calcium sulphate particles in the test liquid (a, $\mathbf{b}, \mathbf{e}-\mathbf{h}$ : microscopy; $\mathbf{c}$ and $\mathbf{d}$ : SEM-images). 


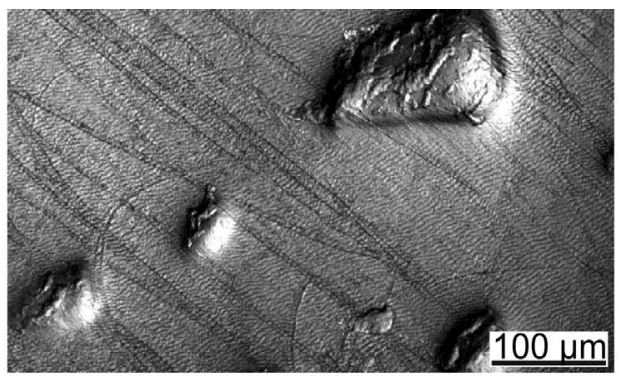

b

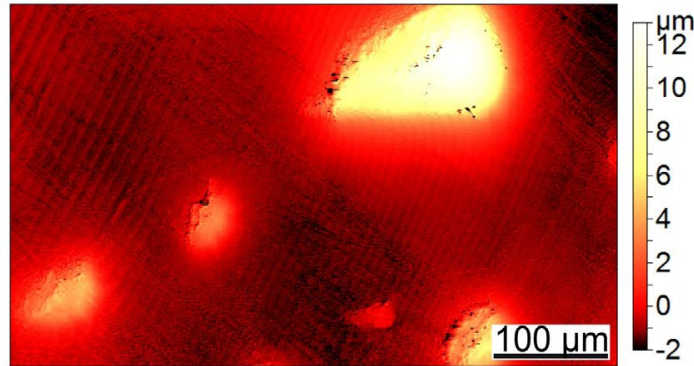

C

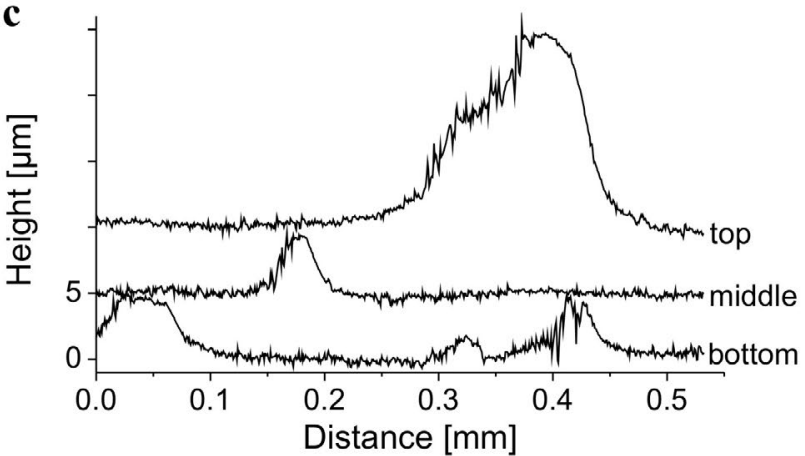

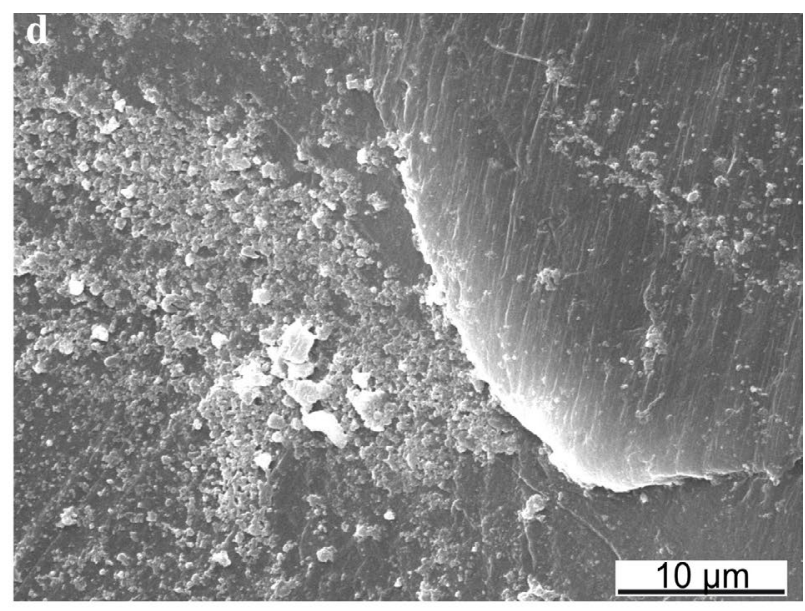

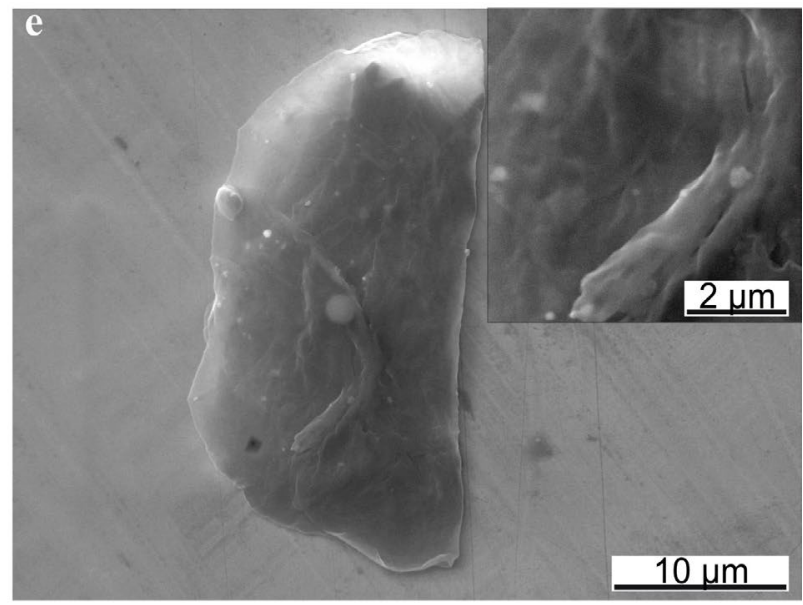

Fig. 5. Transferred material on the anterior wall of an UHMWPE inlay after hip simulator testing in the test liquid containing calcium sulphate particles: (a) intensity and (b) topography determined with confocal microscopy and (c) the profiles extracted along the topography crossing the elevations on the top, in the middle and on the bottom. SEM pictures were taken of the side of such an elevation on the UHMWPE inlay (d) and of an agglomeration of XLPE wear particles on the metallic head (e).

Before the test, the heads were slightly rougher with $\mathrm{R}_{\mathrm{a}}$ of 2-5 $\mathrm{nm}$. The roughness parameter "reduced peak height" $\mathrm{R}_{\mathrm{pk}}$ was reduced during the test, indicating that some of the peaks were removed by abrasion. Additionally, zones with pitting-like irregularities were observed on the anteriorsuperior wall of the inlays. Topography measurements using confocal microscopy showed that these irregularities were actually elevations with a height of 5 to $15 \mu \mathrm{m}$ on the UHMWPE inlays (Fig. 5a-c). More elevations with a height of only about $2 \mu \mathrm{m}$ were present on the XLPE inlays. SEM showed that these elevations were composed of small wear particles, pressed together under the high contact pressure (Fig. 5d). The FT-IR spectra of both the elevations and the worn surface showed the typical spectrum of polyethylene, but with an additional absorption at 1050 and $1110 \mathrm{~cm}^{-1}$, which can be attributed to the $\mathrm{C}-\mathrm{O}$ binding from oxidised polyethylene. This signal was absent in the spectrum of the bulk material. This transferred material was observed independent on the test liquid containing calcium sulphate particles or not. On the metallic heads, few agglomerations of particles were found (Fig. 5e). EDX-Spectra confirmed that these were made of carbon.
The surface of the ceramic heads and inlays was highly polished both before and after the hip simulator test. There were only tiny scratches observed (Fig. 6) together with few pores and some residual proteins. The arithmetic roughness $\mathrm{R}_{\mathrm{a}}$ of the ceramic inlays was $8 \pm 1 \mathrm{~nm}$ before and $7 \pm 3 \mathrm{~nm}$ after the tests. The heads were even smoother with $4 \pm 1 \mathrm{~nm}$ both before and after the test. There was no significant difference in the roughness between the samples before and after the test or between the articulations tested with or without calcium sulphate particles $(p=0.16$ or higher).

\section{Discussion}

\section{Wear of reference samples}

The almost 5 times lower wear rate of the XLPE reference, compared to the UHMWPE reference, is in agreement with in vivo (Mutimer et al., 2010; Johanson et al., 2012) and in vitro data (McNulty et al., 2006; Oral et al., 2006; Bistolfi and Bellare, 2011; Affatato et al., 2012). The wear rate of the ceramic references is also in agreement with the 


\section{Reference}
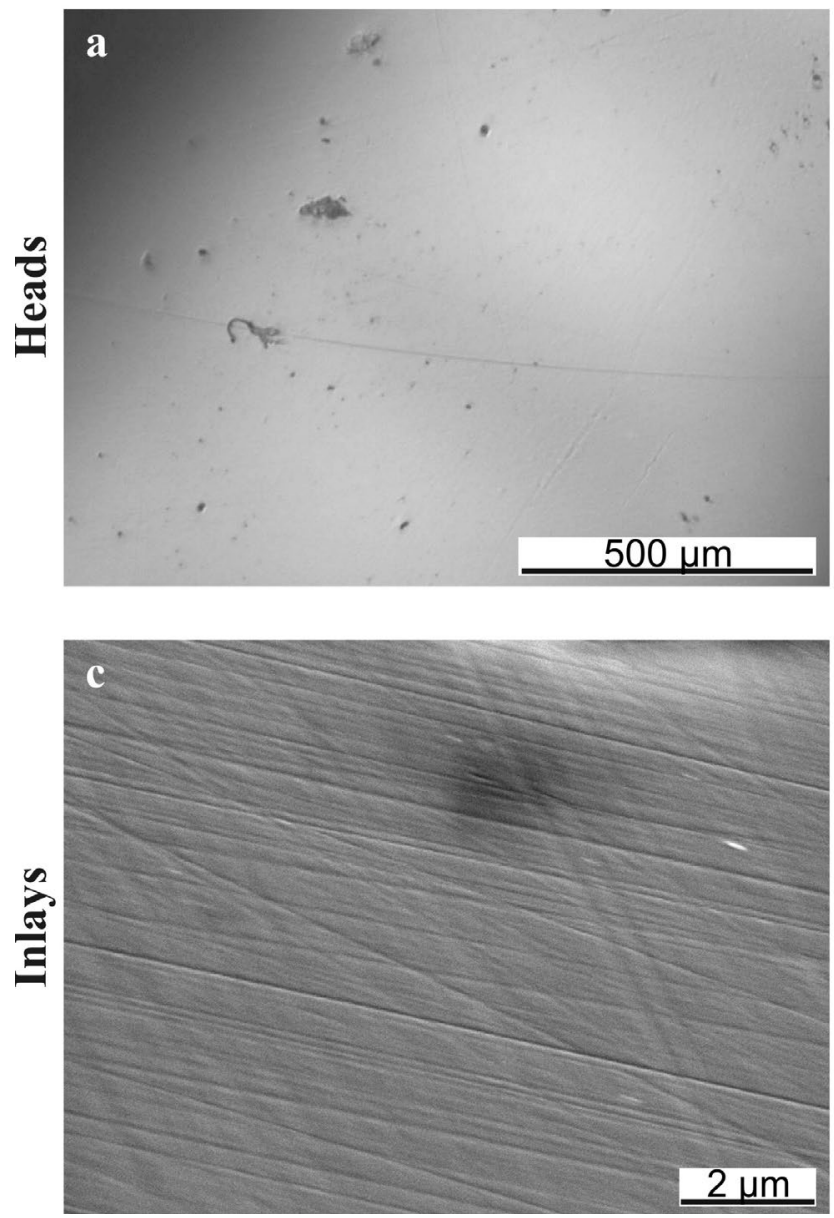

with Calcium Sulphate
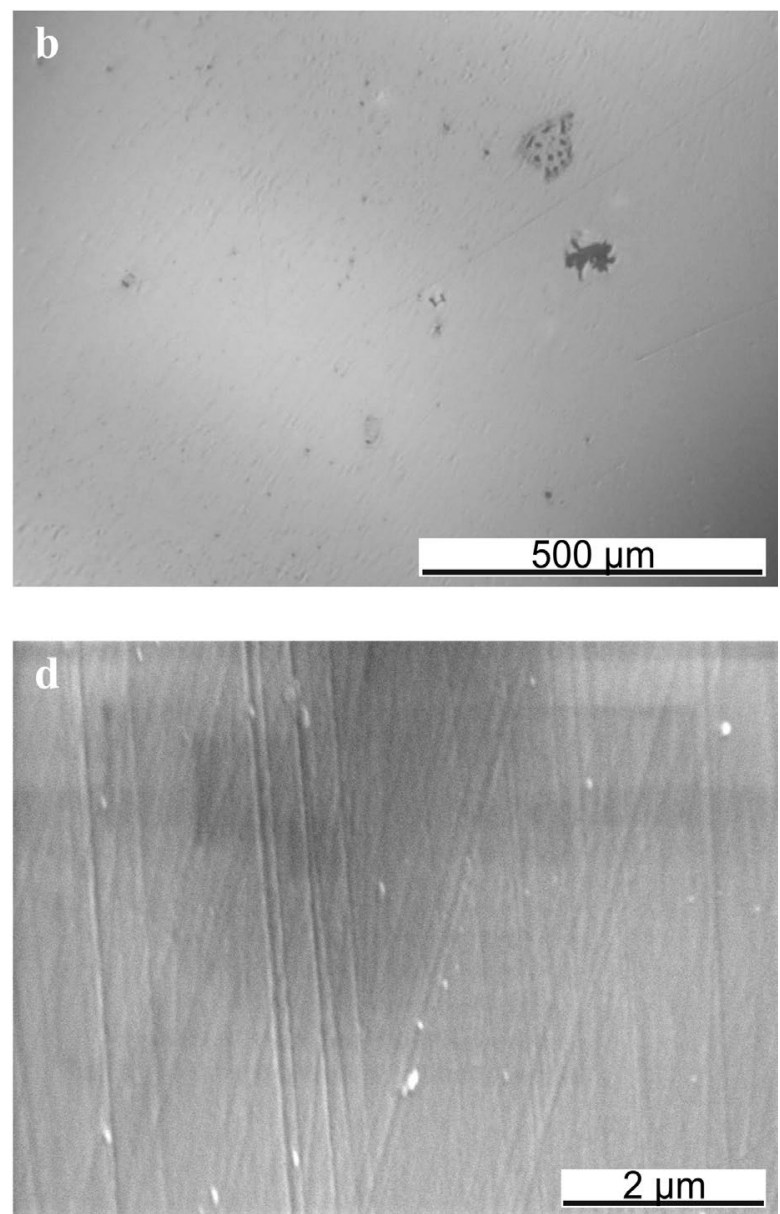

Fig. 6. Microscopic images of the heads (a and $\mathbf{b})$ and SEM pictures of the inlays (c and $\mathbf{d})$ after the hip simulator test with (b and $\mathbf{d})$ and without calcium sulphate particles in the test liquid (a and $\mathbf{c}$ ). The images were taken on the superior part of the samples.

literature (Oberbach et al., 2005). Because the wear rates of the ceramic inlays were close to the detection limit and because of the high scatter of the measured weights of the ceramic inlays and heads, the dimension of the inlays was measured additionally before and after the test, but no significant difference was obtained. This is not very surprising since the expected difference in the radius of the inlays, calculated with the obtained wear rates, is $0.12 \mu \mathrm{m} / 5 \mathrm{MC}$ whereas the resolution of the coordinate measuring machine is $1 \mu \mathrm{m}$. According to Carmignato et al. (2011), the uncertainty of the volumetric wear determined with coordinate measurements is $\pm 3.4 \mathrm{~mm}^{3}$. This is 17 times larger than the obtained, gravimetrical total wear of the inlays. However, the coordinate measurements confirm that the wear rates of the heads and inlays were low.

\section{Third-body wear}

With calcium sulphate particles in the test liquid, the wear rate of the UHMWPE inlays increased by $39 \%$ and the wear rate of the XLPE inlays by $89 \%$, compared to references ( $p=0.07$ and 0.05 respectively). This increase was much smaller compared to third-body wear tests with PMMA particles with a 3 to 20 fold increase (Wang and Essner, 2001; Affatato et al., 2002; Wang and Schmidig,
2003; Oral et al., 2006; Kubo et al., 2009; Sorimachi et al., 2009; Grupp et al., 2014) or with ceramic particles with a 10 to 1000 fold increase (Bragdon et al., 2003; Oberbach et al., 2009b; Hintner et al., 2012). Similar wear rates were obtained only with very small PMMA particles (Bragdon et al., 2003, 2005) or with ceramic-on-polymer instead of metal-on-polymer pairings (Wang and Essner, 2001; Kubo et al., 2009; Grupp et al., 2014). Appending one million cycles without particles led to a significant reduction of the wear, as it was observed by Wang et al. after their PMMA third-body wear tests (Wang and Essner, 2001; Wang and Schmidig, 2003). In this work, the addition of calcium sulphate particles had no significant effect on the alumina articulations. However, even applying small alumina particles (Oberbach et al., 2009b: Ø 1.3-2.6 $\mu \mathrm{m}$ ) or hydroxyapatite particles (Wang et al., 2002) had no significant effect on the wear of ceramic pairings. Only with larger alumina particles was an increase of wear observed in ceramic-on-ceramic pairings (Oberbach et al., 2005, 2009a).

The tests were performed with calcium sulphate without antibiotics in order to not risk the creation of antibiotic resistant bacteria. The implementation of organic material such as antibiotics in the calcium sulphate pellets will lead 
to a weakening of the hardness. Thus the tests with pure calcium sulphate represent a worst case situation.

Since the particle size of the calcium sulphate used (Ø $0.5-100 \mu \mathrm{m})$ was in the same range as that of particles tested in the literature, the main reason for the lower wear in this study must be the mechanical and chemical properties of the particles. The hardness of the calcium sulphate is similar to the hardness of polyethylene (Briscoe et al., 1998), but much softer than CoCrMo or alumina. In contrast, PMMA is harder than polyethylene (Briscoe et al., 1998; Zivic et al., 2012) but softer than common metals or ceramics. This explains why PMMA is able to scratch polyethylene but has little effect on metals and no effect on ceramics (Wang and Essner, 2001; Oral et al., 2006). Ceramics are among the hardest materials, thus ceramic particles can cause severe damage to polymer liners, metallic heads and ceramic counterparts. Once a particle gets into the articulation, possibly by a subluxation of the prosthesis (Heiner et al., 2008), it might become embedded in the polymer (if present) or be trapped between the two articulating surfaces. Since calcium sulphate is a soft and resorbable material, it will most likely be milled into smaller particles, which are slowly dissolved once the synovium is not saturated with calcium and sulphate anymore. Thus, in contrast to the not dissolvable and harder PMMA, metallic or ceramic particles, it does not stay in the articulation for a long time, thus limiting third-body wear. Based on these findings, it can be assumed that applying calcium sulphate particles to ceramic-on-polymer or to mixed ceramic (ATZ, ZTA) articulations will have less or even no adverse effect, compared to the tested pairings.

\section{Transfer film}

Patchy transfer films with elevations of $2 \mu \mathrm{m}$ height on the XLPE and up to $15 \mu \mathrm{m}$ height on the UHMWPE were found on the anterior-superior wall of the inlays, which is the part of the inlay with the highest contact pressure. They are like transfer films, but were not deposited on the counterpart as usual (Walker et al., 1996; Cho et al., 2004) but on the polymer itself. Kaddick and Wimmer (2001) described similar features. These elevations were made of polyethylene particles. Pressing the tip of the FTIR microscope into the elevations led to similar indents to those on the reference spots nearby. This indicates that these elevations were not only loosely bound on the surface, but mechanically stable elevations on the surface. A possible mechanism is that agglomerates of particles as found on the head were continuously sheared off at the zone with the highest contact pressure, building-up the elevations.

\section{"Toxic" microparticles}

With the use of calcium sulphate as antibiotic carrier material, neither the alumina articulations nor the CoCrMo heads were affected. Only the wear of the polymer inlays was increased by 39-89\%. Thus, a larger amount of polyethylene particles is released when calcium sulphate pellets are implanted. Calcium sulphate, however, dissolves within weeks to months (Kelly et al., 2001, Fig. 7c). During this first period, the patient is probably still recovering from the infection and thus presumably less active. Since the heads were not scratched to a greater extent than the reference heads, and since it was shown that the wear rates were reduced to normal values after no more particles were added, no long term damage is likely to occur. The additional particle load that the patient has to deal with is thus limited. The calcium sulphate itself is dissolved into $\mathrm{Ca}^{2+}$ cations, $\mathrm{SO}_{4}{ }^{2-}$ anions and water. These chemicals are present in the body in relatively high concentrations, thus no adverse effect is expected.

\section{Conclusions}

The third-body wear on total hip prostheses was tested in a hip simulator using calcium sulphate particles. Results show that, without particles, the wear rate of XLPE was almost 5 times lower compared to the conventional UHMWPE. Adding calcium sulphate particles led to an increased wear by $39 \%$ for the UHMWPE and by $89 \%$ for the XLPE. The articulations recovered, at least partially, when no more particles were added. Considering the dissolution time of calcium sulphate pellets in vivo of weeks to months, potential wear increase caused by such application is not clinically relevant. The wear of the alumina pairing was not influenced by the presence of calcium sulphate.

All surfaces were slightly scratched, but not more than when compared to tests performed without calcium sulphate particles. Additionally, a patchy transfer film made of small polyethylene particles was found on the superior-anterior wall of the polymer inlays. The metallic heads became smoother during the testing, independent of whether the test was performed with or without particles. The reason for the limited third-body wear is that calcium sulphate is a resorbable and relatively soft material. Thus, if a calcium sulphate particle gets in-between the articulating surfaces, it is probably milled into smaller pieces, which cause less damage. The fact that calcium sulphate is resorbable warrants that trapped or embedded particles cannot remain in the articulation for long.

For ceramic-on-polyethylene articulations and mixed ceramics even less effects by the calcium sulphate are expected, since these heads/materials are more scratch resistant. Thus, calcium sulphate might be used as an antibiotic carrier, even in the presence of total hip prostheses, without fearing excessive third-body wear. While it cannot be claimed from this study that the application of such a local antibiotic carrier has clinically relevant advantages over a classical therapy, it does at least provide essential evidence that doing so would not harm the prosthesis significantly.

\section{Acknowledgments}

The authors would like to thank Olivier Loeffel for taking the SEM-pictures, Fabrizio Bigolin for performing the FT-IR analysis (both RMS Foundation) and Mathys Ltd. for providing the total hip prosthesis components free of charge, especially Thomas Oberbach and Sabine Begand for providing the ceramic parts and for the measurement 

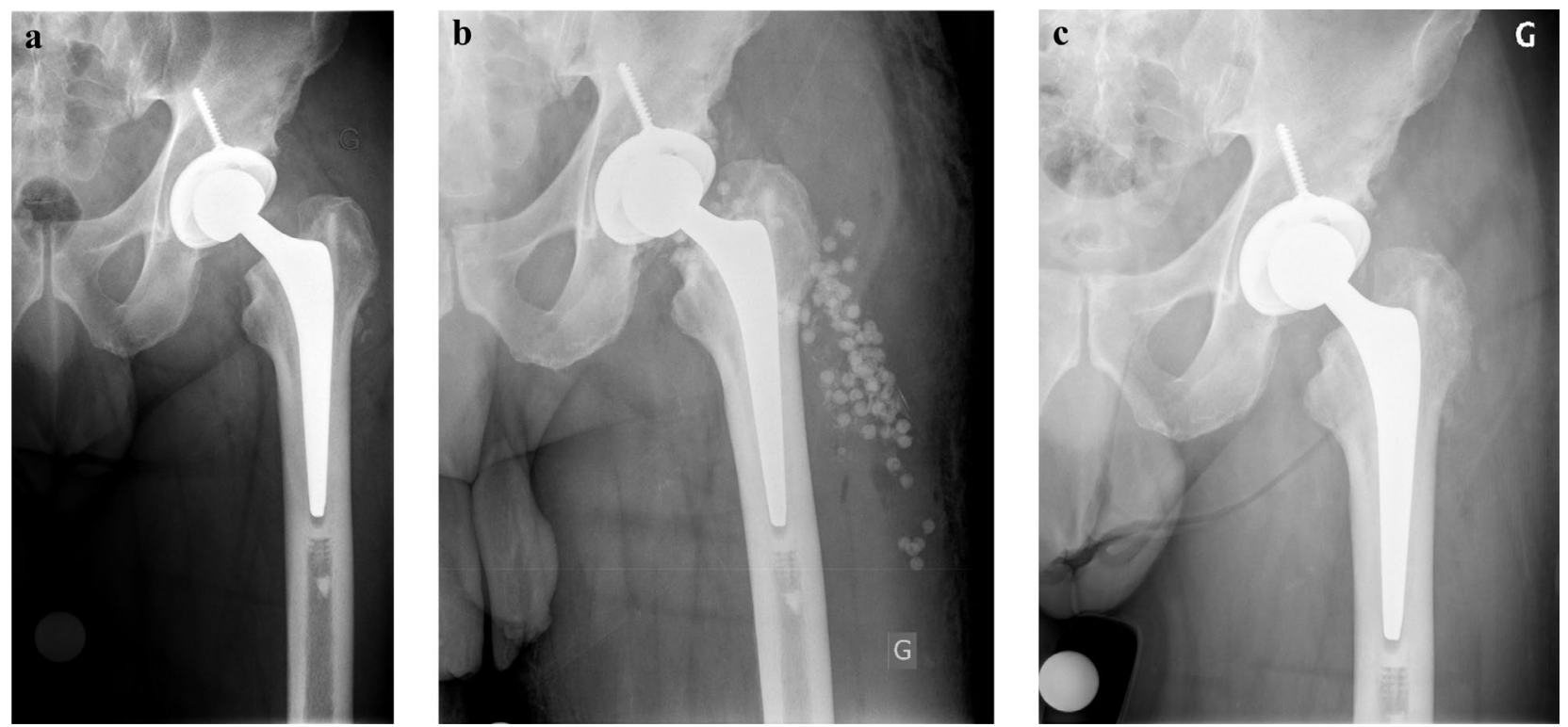

Fig. 7. Zone of interest from conventional anterior-posterior radiographs of the pelvis from the case described, showing his left hip. A hybrid prosthesis with uncemented press-fit cup and cemented double-conical straight stem with a metal on highly cross-linked polyethylene pairing is implanted. (a) Illustrates the situation at admission for the infection. (b) Illustrates the calcium sulphate pellets distributed in the soft tissues around the joint. (c) Is from the follow-up examination at 6 weeks, illustrating the dissolution of the calcium sulphate pellets, which are no longer visible. Note the apparent shortening of the neck due to external rotation of the leg in (b) and to a lesser extent in (c), caused by post-operative weakness of the gluteal muscles.

of the roughness and dimensions of these. Last but not least, the authors thank the RMS Foundation for funding this work.

\section{Appendix}

\section{Case description}

A 63-year-old male patient, otherwise healthy and active, had a total hip replacement on the left side through a lateral, transgluteal approach, for a symptomatic primary osteoarthritis. A hybrid prosthesis with an uncemented press-fit titanium cup with an UHMWPE inlay and a cemented double-conical straight stem with a metallic head (CoCrMo) had been implanted, a combination with one of the lowest long term revision rates (AOANJRR 2013). Follow-up consultation at 6 weeks and 3 months documented a good recovery with no more pain, an excellent range-of-motion and nearly no limping.

At 5 months following the operation, the patient had to be hospitalised for a periprosthetic infection of his left hip. Local symptoms had appeared suddenly 6 days before hospitalisation after some days of flu-like general symptoms. While later manifestation of a post-operative infection always has to be considered at such a short time interval, history rather indicates haematogenous seeding. Anyway, as the duration of symptoms was short and as the implant was well positioned without any signs of loosening (Fig. 7a), the option of debridement and retention of the prosthesis was chosen in agreement with current guidelines (Zimmerli et al., 2004; Haasper et al., 2014).
Debridement and drainage of the hip was performed, including an exchange of the mobile parts, followed by an empirical systemic antibiotic treatment with intra-venous amoxicillin-clavulanate. Staphylococcus aureus, resistant only to penicillin, was identified quickly and the antibiotic treatment could be narrowed by switching to intra-venous flucloxacillin.

After two days and despite adequate treatment, the patient remained febrile. While a second debridement could have been attempted, this situation would usually have to be considered as treatment failure, requiring removal of the implant in order to obtain control of the sepsis (Koyonos et al., 2011; Lora-Tamayo et al., 2013; Haasper et al., 2014). Removal of a well-integrated cup and of a cemented stem without any loosening however has a great risk of causing bone loss and fractures, necessitating complex reconstruction with larger implants than usually required. Considering the life-long risk of further revision in this 63 year-old patient, the option to re-debride the hip, with exchange of the mobile parts and optimisation of antibiotic treatment by implanting a local antibiotic carrier was chosen. In order to avoid major mechanical impingement and requirements for secondary operations for material removal, calcium sulphate, a resorbable rather soft material, was chosen (Kelly et al., 2001). The risk of causing minor to moderate third-body wear was accepted, considering the immediate advantages of infection control and reduced morbidity of potential later aseptic exchange. Calcium sulphate pellets $\left(\varnothing 7 \mathrm{~mm}\right.$, Osteoset ${ }^{\circledR}$ Resorbable Bead Kit, Wright Medical Technology, Memphis, TN, USA) containing the antibiotic vancomycin 
(about 6 wt\%, Vancomycin Labatec, Labatec Pharma, Geneva, Switzerland) were prepared peroperatively. After hardening, they were placed into the soft tissue around the infected joint (Fig. 7b). This is a well-described combination, adequate for this infection, with a prolonged release at high concentrations (Wichelhaus et al., 2001; Rauschmann et al., 2005; Bibbo and Patel, 2006; Heijink et al., 2006; Wang et al., 2011).

During further evolution, symptoms regressed quickly. Following standard procedures, antibiotics were switched from intra-venous to oral after two weeks (Zimmerli et al., 2004; Osmon et al., 2013). An antibiotic combination with high bioavailability and activity against biofilm was chosen, levofloxacin with rifampin, and maintained for 3 months (Zimmerli et al., 2004; Osmon et al., 2013). Dissolution of the calcium sulphate pellets was observed during the expected period of time (Fig. 7c). Except for the persistence of a slight limp, present only with fatigue, the patient recovered fully. More than two years after this event, there was no clinical or radiological sign of recurrence or low-grade persistence of the infection; nor could any asymmetry of the polyethylene liner be identified on the radiographs, as indication of excessive wear.

\section{References}

Affatato S, Bersaglia G, Foltran I, Taddei P, Fini G, Toni A (2002) The performance of gamma- and EtO-sterilised UHWMPE acetabular cups tested under severe simulator conditions. Part 1: Role of the third-body wear process. Biomaterials 23: 4839-4846.

Affatato S, Bracco P, Costa L, Villa T, Quaglini V, Toni A (2012) In vitro wear performance of standard, crosslinked, and vitamin-E-blended UHMWPE. J Biomed Mater Res 100A: 554-560.

Anagnostakos K, Hitzler P, Pape D, Kohn D, Kelm J (2008) Persistence of bacterial growth on antibiotic-loaded beads: Is it actually a problem? Acta Orthopaed 79: 302307.

Australian Orthopaedic Association National Joint Replacement Registry (AOANJRR) (2013) Annual Report.

Bibbo C, Patel DV (2006) The effect of demineralized bone matrix-calcium sulfate with vancomycin on calcaneal fracture healing and infection rates: A prospective study. Foot Ankle Int 27: 487-493.

Bistolfi A, Bellare A (2011) The relative effects of radiation crosslinking and type of counterface on the wear resistance of ultrahigh-molecular-weight polyethylene. Acta Biomater 7: 3398-3403.

Bragdon CR, Jasty M, Muratoglu OK, O’Connor DO, Harris WH (2003) Third-body wear of highly cross-linked polyethylene in a hip simulator. J Arthroplasty 18: 553-561.

Bragdon CR, Jasty M, Muratoglu OK, Harris WH (2005) Third-body wear testing of a highly cross-linked acetabular liner: The effect of large femoral head size in the presence of particulate poly(methyl-methacrylate) debris. J Arthroplasty 20: 379-385.

Briscoe BJ, Fiori L, Pelillo E (1998) Nano-indentation of polymeric surfaces. J Phys D: Appl Phys 31: 2395-2405.
Buchholz HW, Engelbrecht H (1970) Über die Depotwirkung einiger Antibiotica bei Vermischung mit dem Kunstharz Palacos (Depot effects of various antibiotics mixed with Palacos resins). Chirurg 41: 511515.

Carmignato S, Spinelli M, Affatato S, Savio E (2011) Uncertainty evaluation of volumetric wear assessment from coordinate measurements of ceramic hip joint prostheses. Wear 270: 584-590.

Cho HJ, Wei WJ, Kao HC, Cheng CK (2004) Wear behavior of UHMWPE sliding on artificial hip arthroplasty materials. Mater Chem Phys 88: 9-16.

Darouiche RO (2001) Device-associated infections: A macroproblem that starts with microadherence. Clin Infect Dis 33: $1567-1572$.

Darouiche RO (2004) Treatment of infections associated with surgical implants. N Engl J Med 350: 1422-1429.

Doadrio JC, Arcos D, Cabañas MV, Vallet-Regí M (2004) Calcium sulphate-based cements containing cephalexin. Biomaterials 25: 2629-2635.

Elek SD, Conen PE (1957) The virulence of Staphylococcus pyogenes for man. A study of the problems of wound infection. Br J Exp Pathol 38: 573-586.

Grupp TM, Holderied M, Mulliez MA, Streller R, Jäger M, Blömer W, Utzschneider S (2014) Biotribology of a vitamin E-stabilized polyethylene for hip arthroplasty - Influence of artificial ageing and third-body particles on wear. Acta Biomater 10: 3068-3078.

Haasper C, Buttaro M, Hozack W, Aboltins CA, Borens O, Callaghan JJ, de Carvalho PI, Chang Y, Corona P, Da Rin F, Esposito S, Fehring TK, Sanchez XF, Lee GC, Martinez-Pastor JC, Mortazavi SMJ, Noiseux NO, Peng KT, Schutte HD, Schweitzer D, Trebše R, Tsiridis E, Whiteside L (2014) Irrigation and debridement. J Arthroplasty 29: 100-103.

Hauptmann SM, Weber P, Glaser C, Birkenmaier C, Jansson V, Müller PE (2008) Free bone cement fragments after minimally invasive unicompartmental knee arthroplasty: an underappreciated problem. Knee Surg Sports Traumatol Arthrosc 16: 770-775.

Heijink A, Yaszemski MJ, Patel R, Rouse MS, Lewallen DG, Hanssen AD (2006) Local antibiotic delivery with OsteoSet $^{\circledR}, \mathrm{DBX}^{\circledR}$, and Collagraft ${ }^{\circledR}$. Clin Orthopaed Rel Res 451: 29-33.

Heiner AD, Lundberg HJ, Baer TE, Pedersen DR, Callaghan JJ, Brown TD (2008) Effects of episodic subluxation events on third body ingress and embedment in the THA bearing surface. J Biomech 41: 2090-2096.

Hintner M, Kaddick C, Usbeck S, Scheuber L, Streicher RM (2012) What an orthopedic surgeon should know: Selection of a bearing couple in case of revision after a fractured ceramic component. Semin Arthroplasty 23: 241-247.

Iarikov D, Demian H, Rubin D, Alexander J, Nambiar S (2012) Choice and doses of antibacterial agents for cement spacers in treatment of prosthetic joint infections: Review of published studies. Clin Infect Dis 55: 1474-1480.

ISO 4287:1997 Geometrical Product Specifications (GPS) - Surface texture: Profile method - Terms, 
definitions and surface texture parameters. ISO Copyright Office, Geneva, Switzerland.

ISO 4288:1996 Geometrical Product Specifications (GPS) - Surface texture: Profile method - Rules and procedures for the assessment of surface texture. ISO Copyright Office, Geneva, Switzerland.

ISO 13565-2:1996 Geometrical Product Specifications (GPS) - Surface texture: Profile method; Surfaces having stratified functional properties - Part 2: Height characterization using the linear material ratio curve. ISO Copyright Office, Geneva, Switzerland.

ISO 14242-1:2012 Implants for surgery - Wear of total hip-joint prostheses - Part 1: Loading and displacement parameters for wear-testing machines and corresponding environmental conditions for test. ISO Copyright Office, Geneva, Switzerland.

ISO 14242-2:2000 Implants for surgery - Wear of total hip-joint prostheses - Part 2: Methods of measurements. ISO Copyright Office, Geneva, Switzerland.

Johanson PE, Digas G, Herberts P, Thanner J, Kärrholm J (2012) Highly crosslinked polyethylene does not reduce aseptic loosening in cemented THA 10-year findings of a randomized study. Clin Orthopaed Rel Res 470: 30833093.

Kaddick C, Wimmer MA (2001) Hip simulator wear testing according to the newly introduced standard ISO 14242. Proc Inst Mech Eng H 215: 429-442.

Kanellakopoulou K, Giamarellos-Bourboulis EJ (2000) Carrier systems for the local delivery of antibiotics in bone infections. Drugs 59: 1223-1232.

Kelly CM, Wilkins RM, Gitelis S, Hartjen C, Watson JT, Kim PT, Camozzi AB (2001) The use of a surgical grade calcium sulfate as a bone graft substitute: Results of a multicenter trial. Clin Orthopaed Rel Res 382: 42-50.

Kluin OS, Van Der Mei HC, Busscher HJ, Neut D (2013) Biodegradable vs. non-biodegradable antibiotic delivery devices in the treatment of osteomyelitis. Exp Opin Drug Deliv 10: 341-351.

Kohn D, Pape D (2007) Extensive intrapelvic granuloma formation caused by ceramic fragments after revision total hip arthroplasty. J Arthroplasty 22: 293-296.

Koyonos L, Zmistowski B, Della Valle CJ, Parvizi J (2011) Infection control rate of irrigation and débridement for periprosthetic joint infection. Clin Orthopaed Rel Res 469: 3043-3048.

Kubo K, Clarke IC, Sorimachi T, Williams PA, Donaldson TK, Yamamoto K (2009) Aggressive 3rd-body wear challenge to highly crosslinked polyethylene: A hip simulator model. Wear 267: 734-742.

Kurtz SM, Lau E, Watson H, Schmier JK, Parvizi J (2012) Economic burden of periprosthetic joint infection in the United States. J Arthroplasty 27: 61-65.e61.

Lew DP, Waldvogel FA (2004) Osteomyelitis. Lancet 364: 369-379.

Lide DR (2004) The CRC Handbook of Chemistry and Physics. CRC Press, Boca Raton, FL, USA.

Lora-Tamayo J, Murillo O, Iribarren JA, Soriano A, Sánchez-Somolinos M, Baraia-Etxaburu JM, Rico A, Palomino J, Rodríguez-Pardo D, Horcajada JP, Benito N, Bahamonde A, Granados A, Del Toro MD, Cobo J, Riera M, Ramos A, Jover-Sáenz A, Ariza J (2013) A large multicenter study of methicillin-susceptible and methicillin-resistant Staphylococcus aureus prosthetic joint infections managed with implant retention. Clin Infect Dis 56: 182-194.

Marculescu CE, Berbari EF, Hanssen AD, Steckelberg JM, Harmsen SW, Mandrekar JN, Osmon DR (2006) Outcome of prosthetic joint infections treated with debridement and retention of components. Clin Infect Dis 42: 471-478.

McNulty D, Swope S, Liao YS, McKellop H, Shen F-W, Galvin A, Fischer J (2006) Multi-lab evaluation of hip simulator test conditions on relative wear rates of crosslinked polyethylenes. In: Proc 52nd Ann Meeting Orthopaed Res Soc, Chicago, 0649.

Morscher EW, Hefti A, Aebi U (1998) Severe osteolysis after third-body wear due to hydroxyapatite particles from acetabular cup coating. J Bone Joint Surg B80: 267-272.

Mutimer J, Devane PA, Adams K, Horne JG (2010) Highly crosslinked polyethylene reduces wear in total hip arthroplasty at 5 years. Clin Orthopaed Rel Res 468: 3228-3233.

Neut D, Van De Belt H, Stokroos I, Van Horn JR, Van Der Mei HC, Busscher HJ (2001) Biomaterialassociated infection of gentamicin-loaded PMMA beads in orthopaedic revision surgery. J Antimicrob Chemother 47: 885-891.

Oberbach T, Glien W, Kaddick C (2005) Third-bodywear as a risk factor in joint endoprosthetics. Key Eng Mater 284-286: 995-998.

Oberbach T, Begand S, Kaddick C (2009a) Surface resistance of dispersion ceramics against third body abrasion. Key Eng Mater 396-398: 161-164.

Oberbach T, Kempf K, Begand S (2009b) Influence of wear particles on the tribological behaviour of hip couplings after revision. In: Proc Bioceramics 22, Daegu, Korea, pp 325-328.

Oral E, Christensen SD, Malhi AS, Wannomae KK, Muratoglu OK (2006) Wear resistance and mechanical properties of highly cross-linked, ultrahigh-molecular weight polyethylene doped with vitamin E. J Arthroplasty 21: $580-591$.

Osmon DR, Berbari EF, Berendt AR, Lew D, Zimmerli W, Steckelberg JM, Rao N, Hanssen A, Wilson WR (2013) Diagnosis and management of prosthetic joint infection: Clinical practice guidelines by the infectious diseases. Society of America. Clin Infect Dis 56: e1-e25.

Pazzaglia UE, Apostoli P, Congiu T, Catalani S, Marchese M, Zarattini G (2011) Cobalt, chromium and molybdenum ions kinetics in the human body: Data gained from a total hip replacement with massive third body wear of the head and neuropathy by cobalt intoxication. Arch Orthopaed Trauma Surg 131: 1299-1308.

Rauschmann MA, Wichelhaus TA, Stirnal V, Dingeldein E, Zichner L, Schnettler R, Alt V (2005) Nanocrystalline hydroxyapatite and calcium sulphate as biodegradable composite carrier material for local delivery of antibiotics in bone infections. Biomaterials 26: 2677-2684.

Røkkum M, Reigstad A, Johansson CB (2002) HA particles can be released from well-fixed HA-coated stems: Histopathology of biopsies from 20 hips 2-8 years after implantation. Acta Orthopaed Scand 73: 298-306. 
Rönn K, Wahl P, Bohner M, Decosterd L, Festa S, Gautier E (2014) In vitro study of new combinations for local antibiotic therapy with calcium sulphate near-constant release of ceftriaxone offers new treatment options. In: SGOT, 74. Jahreskongress, St. Gallen, Switzerland: FM5.

Scott DL, Campbell PA, McClung CD, Schmalzried TP (2000) Factors contributing to rapid wear and osteolysis in hips with modular acetabular bearings made of Hylamer. J Arthroplasty 15: 35-46.

Sorimachi T, Clarke IC, Williams PA, Gustafson A, Yamamoto K (2009) Third-body abrasive wear challenge of $32 \mathrm{~mm}$ conventional and $44 \mathrm{~mm}$ highly crosslinked polyethylene liners in a hip simulator model. Proc Inst Mech Eng H 223: 607-623.

Van De Belt H, Neut D, Schenk W, Van Horn JR, Van Der Mei HC, Busscher HJ (2001) Staphylococcus aureus biofilm formation on different gentamicin-loaded polymethylmethacrylate bone cements. Biomaterials 22: 1607-1611.

Vanhegan IS, Malik AK, Jayakumar P, Ul Islam S, Haddad FS (2012) A financial analysis of revision hip arthroplasty. J Bone Joint Surg 94B: 619-623.

Wahl P, Livio F, Jacobi M, Gautier E, Buclin T (2011a) Systemic exposure to tobramycin after local antibiotic treatment with calcium sulphate as carrier material. Arch Orthopaed Trauma Surg 131: 657-662.

Wahl P, Livio F, Jacobi M, Gautier E, Buclin T (2011b) Wound fluid and serum concentrations of vancomycin after local therapy with calcium sulphate as carrier material. In: 12th EFORT Congress, JBJS, Copenhagen, Denmark, J Bone Joint Surg Br (2012) 94-B, Supp XXXVII: 79.

Walker PS, Blunn GW, Lilley PA (1996) Wear testing of materials and surfaces for total knee replacement. J Biomed Mater Res 33: 159-175.

Wang A, Essner A (2001) Three-body wear of UHMWPE acetabular cups by PMMA particles against $\mathrm{CoCr}$, alumina and zirconia heads in a hip joint simulator. Wear 250-251: 212-216.

Wang A, Schmidig G (2003) Ceramic femoral heads prevent runaway wear for highly crosslinked polyethylene acetabular cups by third-body bone cement particles. Wear 255: 1057-1063.
Wang A, Chopra A, Schmidig G (2002) Ceramic-onceramic bearing surfaces: A complete solution to 3rd-body wear problem in total hip arthroplasty. Key Eng Mater 218-220: 669-672.

Wang Y, Wang X, Li H, Xue D, Shi Z, Qi Y, Ma Q, Pan Z (2011) Assessing the character of the rhBMP-2- and vancomycin-loaded calcium sulphate composites in vitro and in vivo. Arch Orthopaed Trauma Surg 131: 991-1001.

Wichelhaus TA, Dingeldein E, Rauschmann M, Kluge S, Dieterich R, Schäfer V, Brade V (2001) Elution characteristics of vancomycin, teicoplanin, gentamicin and clindamycin from calcium sulphate beads. J Antimicrob Chemother 48: 117-119.

Widmer AF, Frei R, Rajacic Z, Zimmerli W (1990) Correlation between in vivo and in vitro efficacy of antimicrobial agents against foreign body infections. J Infect Dis 162: 96-102.

Wolf CF, Gu NY, Doctor JN, Manner PA, Leopold SS (2011) Comparison of one and two-stage revision of total hip arthroplasty complicated by infection a markov expected-utility decision analysis. J Bone Joint Surg 93A: 631-639.

Zimmerli W, Waldvogel FA, Vaudaux P, Nydegger UE (1982) Pathogenesis of foreign body infection: Description and characteristics of an animal model. J Infect Dis 146: 487-497.

Zimmerli W, Lew PD, Waldvogel FA (1984) Pathogenesis of foreign body infection. Evidence for a local granulocyte defect. J Clin Invest 73: 1191-1200.

Zimmerli W, TrampuzA, Ochsner PE (2004) Prostheticjoint infections. N Engl J Med 351: 1701-1703.

Zivic F, Babic M, Grujovic N, Mitrovic S, Favaro G, Caunii M (2012) Effect of vacuum-treatment on deformation properties of PMMA bone cement. J Mech Behav Biomed Mater 5: 129-138.

Editor's Note: All questions/comments by the reviewers were answered by text changes. There is hence no Discussion with Reviewers section. 